\title{
EFFECT OF ASCORBIC, HUMIC AND NICOTINIC ACIDS ON CERTAIN BIOCHEMICL CONSTITUENTS FENUGREEK (Trigonella foenum-graecum $L$ )
} Mohamed, Z.A.; M.F. El-Banna and A.S.A.M. Shabara Agric. Bot. Dept., Faculty of Agric., Mansoura University, 35516, El-Mansoura, Egypt

\begin{abstract}
Two field experiments were conducted to evaluate the effects of ascorbic (AsA), humic (HA) and nicotinic (NA) acid on certain biochemical constituents that influence seed quality of Fenugreek (Trigonella foenum-graecum L.). Results indicated that presoaking or presoaking plus spraying in by AsA, HA and NA increased flavonoids, alkaloids, trigonelline, protein, total carbohydrates and oil percentage in seeds. With all tested metabolic inducers (MI), the enhancing effect was more pronounced at its higher adopted level and when it was applied as a combined presoaking plus a foliar spray treatment. Total alkaloid percentage was highest in response to $\mathrm{HA}$ at $3000 \mathrm{mg} / \mathrm{l}$ whereas trigonelline percentage recorded highest value in response to AsA at $200 \mathrm{mg} / \mathrm{l}$. On the other hand, total phenols percentage was generally decreased with exogenous application of all $\mathrm{MI}$, and the reduction was more evident at the higher level of either AsA, HA or NA. Based on the obtained results, it could be concluded that metabolism of Fenugreek (Trigonella foenum-graecum L.) could be modulated toward the accumulation of beneficial components by exogenous application of AsA, HA, and NA.
\end{abstract}

\section{INTRODUCTION}

Fenugreek (Trigonella foenum-graecum L.) is known as one of the oldest medicinal plants recognized in recorded history (Acharya et al., 2008). Fenugreek leaves and seeds are consumed in different countries around all the world for different purposes, the most prominent of which are its medicinal uses. Medicinally, it is used as anti-diabetic, lowering blood sugar and cholesterol levels, anticancer, and antimicrobial (Mehrafarin et al., 2011). Fenugreek above-ground organs contain several bioactive compounds including flavonoids, phenols and alkaloids, the most important of which is trigonelline (Snehlata and Payal, 2012). Trigonelline have several physiological effects the most notably of which are its hypoglycemic effect (Turky Neveen, 2007; Abd-El Mawla and Osman, 2011). Secondary metabolites biosynthesis and accumulation could be enhanced through application of plant growth regulators (Danesh-Talab et al., 2014) or certain elicitors (Abd-El Mawla and Osman, 2011). Benzylaminopurine (Ortuno et al., 1998), 2-1-napthyl acetic acid (Alagukannan and Vijaykumar, 1999), and both GA3 and NAA applied at various concentrations (Danesh-Talab et al., 2014) have been reported to have enhancing effects on certain Fenugreek seed metabolites. However, little is known about the effects of ascorbic and humic acids on the biosynthesis and accumulation of secondary metabolites in Fenugreek. Elicitation and precursor feeding are two common approaches for enhancing secondary metabolites biosynthesis and accumulation. Methyl Jasmonate (MJ) was used as an elicitor for trigonelline induction in 
Fenugreek cell suspension cultures (Abd-El Mawla and Osman, 2011). They reported a 2-fold increase in trigonelline percentage in MJ-elicited cultures. In addition, precursor feeding with Nicotinic acid (NA) was found to enhance trigonelline content in callus cultures of Moringa Oleifera (Mathur and Kamal, 2012). On the other hand, the effectiveness of precursor feeding with NA in vivo is less investigated and poorly understood. Therefore, the present investigation was conducted to assess the effects of in vivo application of ascorbic, humic and nicotinic acids on key secondary metabolites as well as major seed constituents of Fenugreek.

\section{MATERIALS AND METHODS}

Two field experiments were established during the two growth season 2012/2013 and 2013/2014. In the soaking treatment, seeds were soaked in solution of AsA and NA either at 100 or $200 \mathrm{mg} / \mathrm{L}$ as well as in HA either at 1500 or $3000 \mathrm{mg} / \mathrm{L}$ for $5 \mathrm{~h}$. Seeds soaked in distilled water for the same period represent the control treatment. Soaked seeds were inoculated with Rhizobium sp before sowing at $15 \mathrm{~cm}$ apart in $2 \times 3 \mathrm{~m}$ plots. In the combined soaking plus spraying treatment, plants were also received two foliar applications with the same metabolic inducers (Mls) and at the same level used in soaking. The first foliar spray was 30 days after sowing (DAS) whereas the second was 45 DAS. Except for treatment with either MI, all other tillage practices were followed as recommended by the Ministry of Agriculture Egypt. The experiment was laid out in a randomized complete block design. At the end of the growing season after 140 days from sowing, seed samples were collected to determine certain biochemical constituents. Some physical and chemical properties of the experimental soil are listed in Table 1, soil analysis was carried out according to Hesse (1971).

Table (1): Physical and chemical properties of the experimental soil.

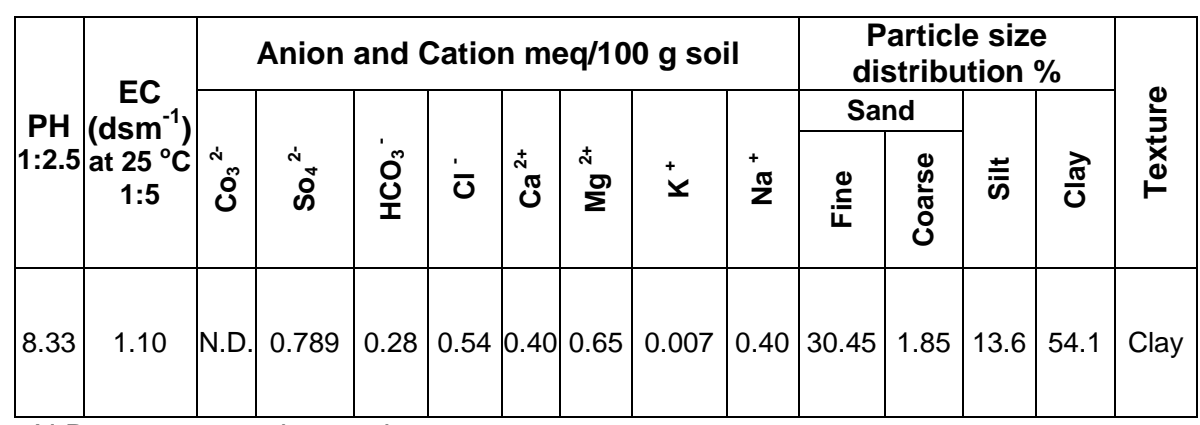

N.D., means not detected

\section{Determination of total carbohydrate:}

A $5 \mathrm{~g}$ seed sample was extracted by ethanol $(80 \%)$ and kept overnight at room temperature. The ethanolic extract was used for the determination of total carbohydrates using anthrone method. The developed green color was measured spectrophotometrically at $630 \mathrm{~nm}$ according to Sadasivam and Manickam (1996). 


\section{Determination of total alkaloids:}

Total alkaloids were determined using the method that described by Aziz et al. (2005) by Soxhlet. Ten grams of the powdered sample seeds was extracted with $250 \mathrm{~mL}$ of ethanol for five hours, extracted of ethanol was evaporated to dryness with a rotary evaporator, under reduced pressure at 40 ${ }^{\circ} \mathrm{C}$. Dry residue was repeat by $150 \mathrm{~mL}$ of chloroform and acidified by $\mathrm{HCL} 15 \%$ up to $\mathrm{pH} 3$, it let pillow during 30 minutes in the room temperature, the phase acid aqueous were extracted by $150 \mathrm{~mL}$ of chloroform, basify by the $\mathrm{NaHCO} 35 \% \mathrm{pH} 9$ and lit it during 15 minutes in the room temperature. The chloroform phase was evaporated to dryness with a rotary evaporator under reduced pressure. The dry residue is the total alkaloid.

\section{Determination of total phenols:}

The powdered seed $(2 \mathrm{~g})$ was extracted with methanol, at room temperature overnight. The methanol extracts were combined and concentrated under reduced pressure on a rotary evaporator. Total phenolic percentage of each plants extract was determined with the Folin-Ciocalteu's reagent (FCR) according to Slinkard and Singleton (1977). Each sample $(0.5 \mathrm{ml})$ was mixed with $2.5 \mathrm{ml}$ FCR (diluted $1: 10, \mathrm{v} / \mathrm{v}$ ) followed by $2 \mathrm{ml}$ of $\mathrm{Na} 2 \mathrm{CO} 3(7.5 \%$, v.v) solution. The absorbance was then measured at $765 \mathrm{~nm}$ after incubation at $30{ }^{\circ} \mathrm{C}$ for 90 minutes. Results were expressed as Gallic acid equivalent (mg Gallic acid/100g dried extract).

\section{Determination of flavonoid:}

The total flavonoid percentage of seed extract was determined by a colorimetric method as described in by (Zhishen et al., 1999). Each sample $(0.5 \mathrm{ml})$ was mixed with $2 \mathrm{ml}$ of distilled water and subsequently with $0.15 \mathrm{ml}$ of a $\mathrm{NaNO}_{2}$ solution (15\%). After 6 minutes, $0.15 \mathrm{~mL}$ of aluminum chloride $\left(\mathrm{AlCl}_{3}\right)$ solution $(10 \%)$ was added and allowed to stand for 6 minutes, then 2 $\mathrm{mL}$ of $\mathrm{NaOH}$ solution (4\%) was added to the mixture, mixed thoroughly and allowed to stand for another 15 minutes at room temperature. Absorbance of the mixture was then determined at $510 \mathrm{~nm}$ versus prepared water blank.

Determination of protein:

Percentage of protein was calculated by multiplying the percentage of total nitrogen by the factor of 6.25 (A.O.A.C., 1980).

$\%$ Protein $=\%$ Nitrogen $\times 6.25$.

Determination of Trigonelline:

By Seed percentage of the active ingredient were taken 100 grams of seeds of each experimental unit and underwent grinding and sieving operations since taking 80 grams of seeds crushed to remove fat and processed for the extraction process for vehicles. After Alkaloids remove fat from seeds according to the method (Wagner et al., 1984). Then it was separated and purified compounds to take 40 grams of residue seeds were extracted defatted Alkaloids and purified according to the method (Tugrul and Ozer, 1985).

\section{Determination of Fixed oil:}

The percentage of fixed oil in seeds was determined according to the method mentioned by A.O.A.C (1980). 
It could be mention that chemical determination was made only in the first season 2012/2013.

Statistical analysis:

The obtained data were subjected to statistical analysis according to Gomez and Gomez (1984). The treatment means were compared using the least significant difference (LSD).

\section{RESULTS AND DISCUSSION}

\section{Effect of AsA:}

Ascorbic acid applied at $200 \mathrm{mg} / \mathrm{L}$ increased significantly all studied seed biochemical characters; however. It led to reduce total phenols (Fig. 4). At $100 \mathrm{mg} / \mathrm{L}$, AsA increased total flavonoids (Fig. 3), trigonelline (Fig. 1), total carbohydrates and oil percentages (Table 2) whereas did not significantly affect other studied characters. At both AsA levels, its application as a combined presoaking plus foliar spray treatment was superior to its application as a presoaking treatment only. Highest alkaloids and trigonelline percentages were obtained in case of the interaction between the combined application methods with AsA at $200 \mathrm{mg} / \mathrm{L}$.

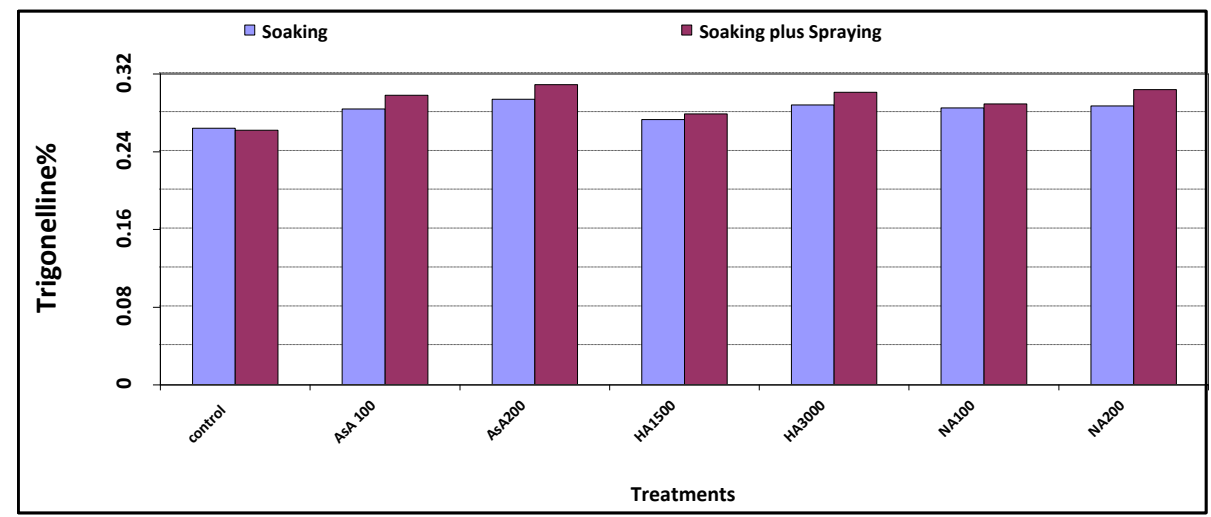

Figure (1): Effect of exogenous application with ascorbic (AsA), humic (HA) and nicotinic (NA) acids on trigonelline percentage in Fenugreek seeds after (140) days from sowing. 


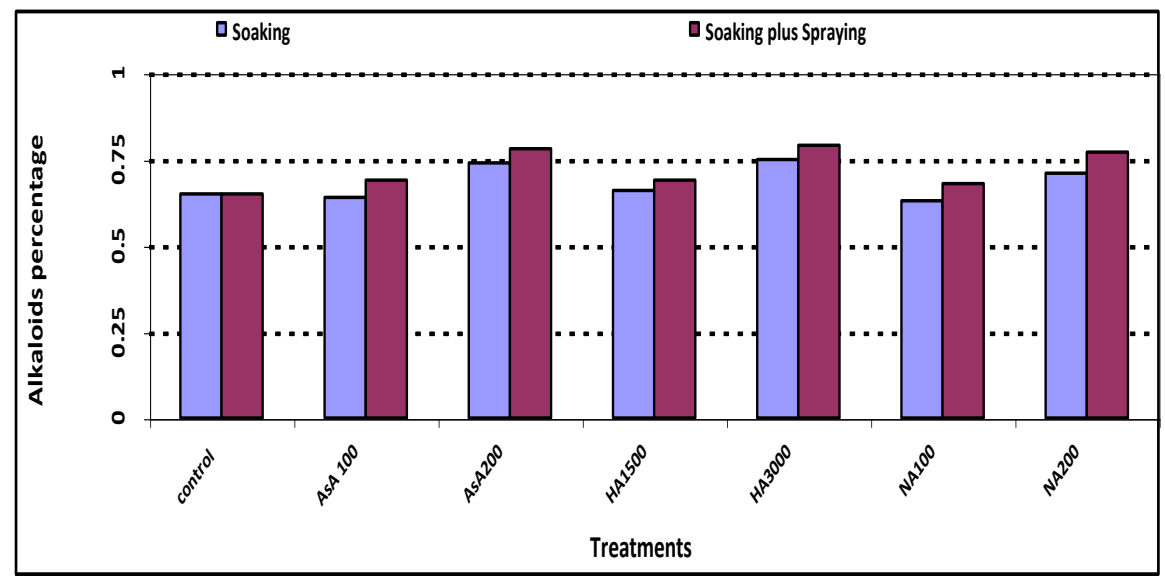

Figure (2): Effect of exogenous application with ascorbic (AsA), humic (HA) and nicotinic (NA) acids on alkaloids percentage in Fenugreek seeds after (140) days from sowing.

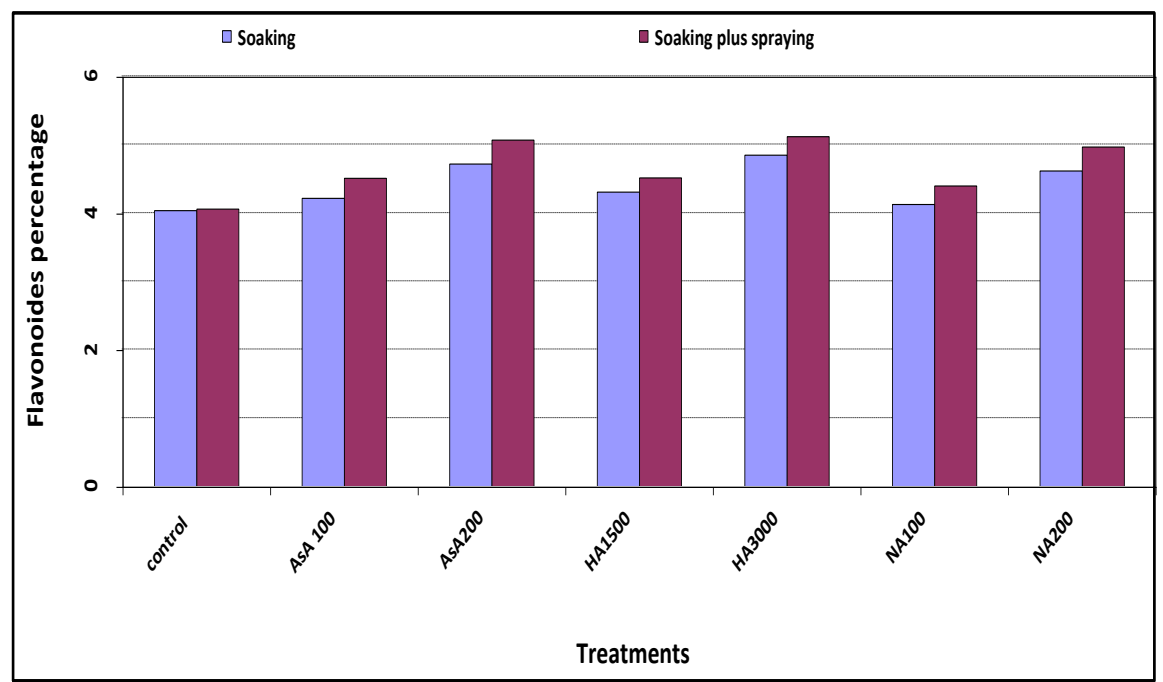

Figure (3): Effect of exogenous application with ascorbic (AsA), humic (HA) and nicotinic (NA) acids on flavonoids percentage in Fenugreek seeds after (140) days from sowing.

AsA is involved in a wide range of important functions in plant growth and metabolism. It has a fundamental role as defense antioxidant as well as essential roles in photoprotection, regulation of photosynthesis and growth (El-Lethy et al., 2011). As primary and secondary plant metabolism are closely interconnected, it may be concluded that AsA-induced stimulating flavonoids, alkaloids and trigonelline synthesis, which associated with its stimulating effects on plant primary metabolism/metabolites (Table 2). This conclusion is substantiated with the results of previous investigations in which 
exogenous application of AsA was reported to enhance photosynthetic activity and various plant primary metabolites in Lycopersicon esculentum (EI Sayed and El Sayed, 2013). In addition, AsA application was found to increase total phenols and total flavonoids in two different genotypes of maize (Salama et al., 2013), as well as various secondary metabolites in Pelargonium graveolens (E-Lethy et al., 2011) and Jasminum grandiflorum (Aid Rawia, et al., 2010).

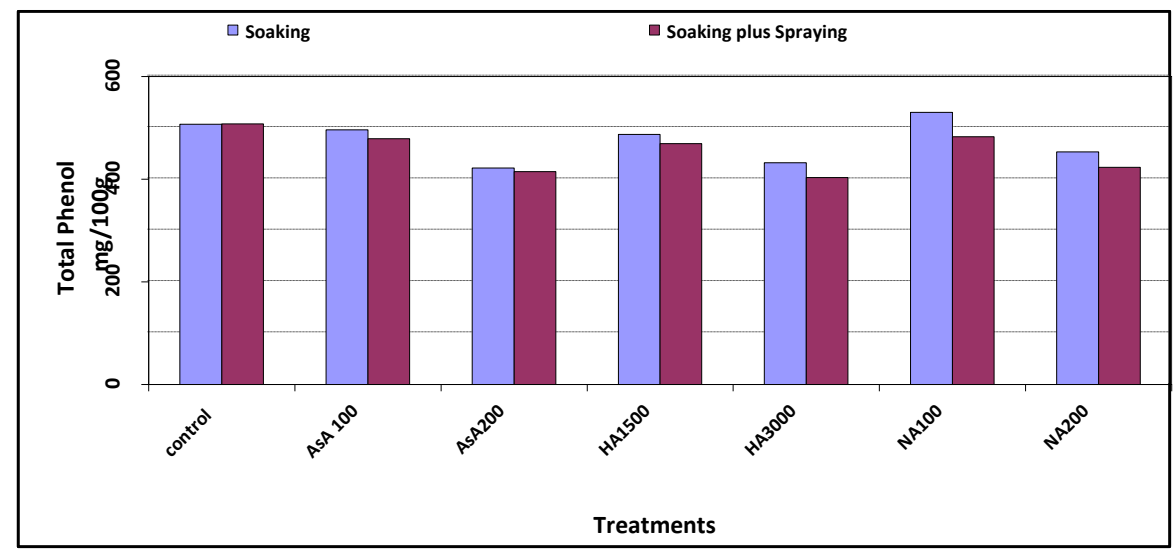

Figure (4): Effect of exogenous application with ascorbic (AsA), humic (HA) and nicotinic (NA) acid on total phenol in Fenugreek seeds after (140) days from sowing.

\section{Effects of HA:}

$\mathrm{HA}$ applied at $3000 \mathrm{mg} / \mathrm{L}$ increased all recorded parameters. On the other hand, total phenols percentage showed a noticeable reduction (Fig. 4). At its lower adopted level (1500 mg/L), HA increased total flavonoids, trigonelline, total carbohydrates and oil percentage (Table 2). Whereas other parameters were not significantly affected. Higher increment levels were recorded when HA was applied as presoaking in conjunction with a foliar spray treatment. When considering the interaction between $\mathrm{HA}$ levels and application methods, the interaction between $\mathrm{HA}$ at $3000 \mathrm{mg} / \mathrm{L}$ and the combined method of application was of superior effect (Figures 1-4 and Table 2).

HA was previously reported to both directly and indirectly affect plant's biochemical processes (Yang et al., 2004; Rady, 2012). HA was reported to positively influence net photosynthesis along with enhancing chlorophyll percentage and stomatal conductance (Tahir et al., 2013). In addition, the activity of two key photosynthetic enzymes, phosphoenolpyruvate carboxylase and ribulose-1,5- bis phosphate carboxylase was enhanced in response to HA treatment (Zhang et al., 2014). Total sugars, total free amino acids and protein concentrations were increased in snap bean treated with HA (Hanafy et al., 2010). In their study, total phenols percentage was also increased in response to $\mathrm{HA}$, in contrary to the results of the present investigation. This could be explained by lower HA concentration used in their study, being $2000 \mathrm{mg} / \mathrm{L}$. Inhibition of urease activity by humic acid was 
reported by Vaughan and Ord (1991), which may reduce $\mathrm{N}$ loss by volatilization, thereby increase $\mathrm{N}$ availability to plants which enhance plant biochemical processes in which $\mathrm{N}$ is involved. Trevisan et al. (2010) concluded a HA- dependent activation of plant biochemical processes and enzymes synthesis as well as auxin-like activities of HA which resulted in increased root mass, photochemical efficiency and antioxidant levels. In addition, Zhang and Ervin (2004) found that exogenous application of HA increased endogenous cytokinin and auxin levels, which may improve crop productivity.

Table (2): Effects of exogenous application with ascorbic (AsA), humic (HA) and nicotinic (NA) acid on protein \%, total carbohydrates $\%$ and fixed oil \% in seeds after (140) days from sowing.

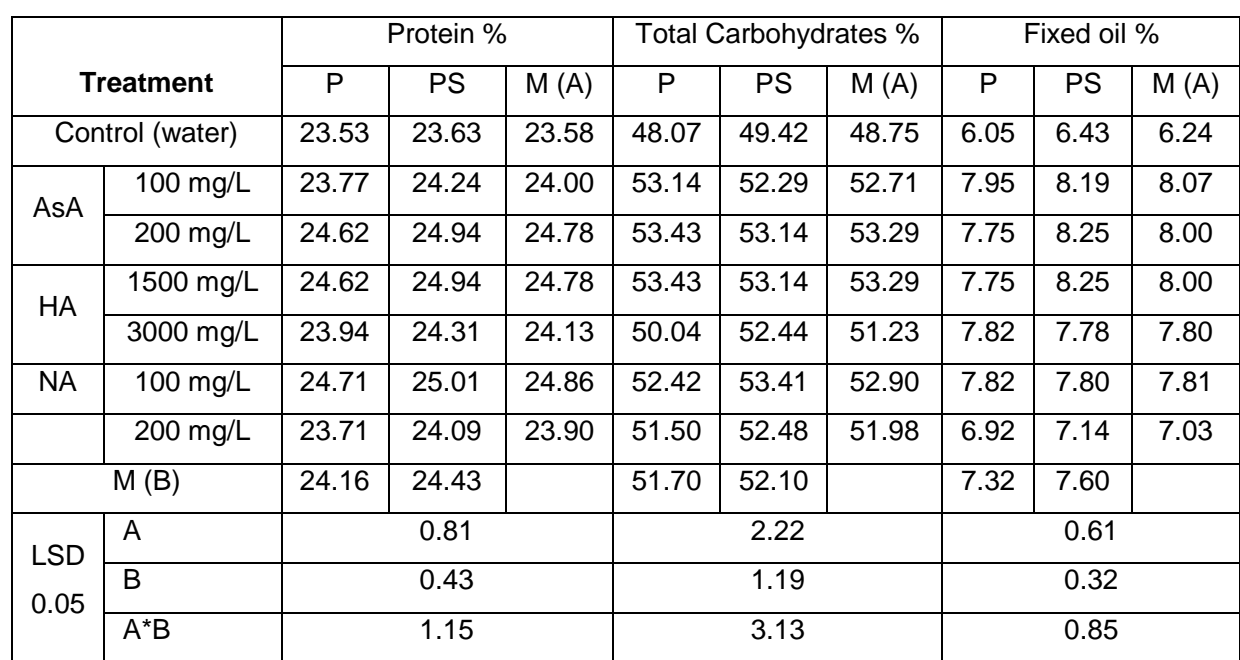

P, presoaking; PS, presoaking plus spraying; M, Mean

\section{Effect of Nicotinic acid (NA):}

$N A$, at both levels increased trigonelline, total carbohydrates and oil percentage. On the other hand, total flavonoids, total alkaloids and protein percentage were increased only when NA was applied at $200 \mathrm{mg} / \mathrm{L}$ (Figures 1-4 and Table 2). Total phenols percentage decreased in response to the higher level, whereas it was not affected in response to the lower level NA. Application of NA as a combined presoaking plus spraying treatment was more effective in inducing secondary metabolites accumulation in fenugreek seeds. Nevertheless, more reduction in total phenols percentage was recorded due to the combined treatment (Fig. 4). NA and NAD are chemically related (Ali, 2002), so similar effects of both on plant growth and metabolism is envisaged. Both NA and NAD increased ricinine alkaloids and oil percentage in Ricinus communis plants grown under salinity stress (Ali, 2002). He concluded that adequate supply of NAD through NA application is 
essential for normal plant growth and development. This may explain the positive effects of NA exogenous application on the recorded biochemical constitutes. Trigonelline serves as storage form of NA (Mathur and Kamal, 2012). So, trigonelline accumulation due to NA application recorded in the present investigation may be explained on the ground that nicotinic acid acted as a precursor in the biosynthesis of trigonelline in Fenugreek. This conclusion is supported by the result of previous studies in which trigonelline formation was increased in NA-supplemented tissue cultures of Trigonella foenum-graecum (Khanna and Jain,1972), Allium cepa (Khanna et al.,1989) and Moringa olifera (Mathur and Kamal, 2012).

\section{REFERENCES}

Abd-El Mawla, A.M.A. and Osman, H.E.H. (2011). Elicitation of Trigonelline and 4-Hydroxyisoleucine with Hypoglycemic Activity in Cell Suspension Cultures of Trigonella foenum-graecum L. The Open Conference Proceeding J., 2: 80-87.

Acharya, S.N.; Thomas, J.E. and Basu, S.K. (2008). Fenugreek, an alternative crop for semiarid regions of North America. Crop Sci., 48: 841-853.

Aid, E. Rawia; Lobna, S. Taha and Soad, M.M. Ibrahim (2010). Physiological properties studies on essential oil of Jasminum grandiflorum $\mathrm{L}$. as affected by some vitamins. Ozean J. of Appl. Sci., 3: 87-96.

Alagukannan, G. and Vijaykumar, M. (1999). Effect of plant growth substances on yield attributing parameters, yield and quality in fenugreek (Trigonella foenum-graceum Linn). S. Indian Horticulture, 47: 130-133.

Ali, R.M. (2002). Effect of nicotinic acid and nicotinamide adenine dinucleotide on growth and content of oil, glycerol and ricinine alkaloids of salinity stressed Ricinus communis L. Phyton., 42: 269-277.

A.O.A.C. (1980). Official Methods of analysis "Association of Official Agricultural Chemists", $13^{\text {th }}$ ed. Washington, D.C., USA.

Aziz, B.; Boughdad, A. and Blenzar, A. (2005). Effets biocides des alcaloïdes, des saponines et des flavonoïdes extraits de Capsicum frutescens $\mathrm{L}$. (Solanaceae) sur Bemisia tabaci (Gennadius) (Homoptera: Aleyrodidae). Biotechnol. Agron. Soc. Environ., 9: 259-269.

Danesh-Talab, S.; Mehrafarin, A.; Lobbafi, M.; Qavami, N.; Qaderi, A. and Naghdi Badi, H. (2014). Responses of Fenugreek (Trigonella foenumgraecum L.) to exogenous application of plant growth regulators $\left(P_{G}\right)$. Trakia J. of Sci., 2: 142-148.

El Sayed, H. and El Sayed, A. (2013). Exogenous application of ascorbic acid for improve germination, growth, water relations, organic and inorganic components in tomato (Lycopersicon esculentum Mill.) plant under saltstress. New York Science J., 6: 123-139.

El-Lethy, S.R.; Ayad, H.S. and Reda, F. (2011). Effect of riboflavin, ascorbic acid and dry yeast on vegetative growth, essential oil pattern and antioxidant activity of geranium (Pelargonium graveolens L.). AmericanEurasian J. of Agric. and Environ. Sci., 10: 781-786. 
Gomez, K.A. and Gomez, A.A. (1984). Statistical Procedures for Agriculture Research. John Wiley and Sons, Inc. New York.

Hanafy, A.A.H.; Nesiem, M.R.; Hewedy, A.M. and Sallam, H. El-S. (2010). Effect of some simulative compounds on growth, yield and chemical composition of snap bean plants grown under calcareous soil conditions. J. of Amer. Sci., 6: 552-569.

Hesse, P.R. (1971). A text book of soil chemical analysis. Juan Murry (Publisher) Ltd., London.

Khanna, P. and Jain, S.C. (1972). Effect of nicotinic acid on growth and production of trigonelline by Trigonella foenum-graecum $\mathrm{L}$. tissue cultures. Indian J. Exp. Biol., 10: 248-249.

Khanna, P.; Sharma, A.; Kaushik, P. and Chaturvedi, P. (1989). Trigonelline from three plant species in vivo and in vitro tissue cultures. Invest New Drug, 26: 334-336 .

Mathur, M. and Kamal, R. (2012). Studies on trigonelline from Moringa oleifera and its in vitro regulation by feeding precursor in cell cultures. Revista Brasileira de Farmacognosia, 22: 994-100.

Mehrafarin, A.; Rezazadeh, Z.S.H.; Naghdi, B.H.; Noormohammadi, G.H.; Zand, E. and Qaderi, A. (2011). A review on biology, cultivation and biotechnology of fenugreek (Trigonella foenum-graecum $\mathrm{L}$.) as a valuable medicinal plant and multipurpose. J. of Medicinal Plants, 10: 6-24.

Ortuno, A.; Oncina, R.; Botia, J.M. and Del Rio, J.A. (1998). Distribution and changes of diosgenin during development of Trigonella foenum-graecum plants. Modulation by benzylaminopurine. Food Chem., 63: 51-54.

Rady, M.M. (2012). A novel organo-mineral fertilizer can mitigate salinity stress effects for tomato production on reclaimed saline soil. South Afr. J. of Bot., 81: 8-14.

Sadasivam, S. and Manickam, A. (1996). Biochemical Methods, $2^{\text {nd }}$ Ed. New Age International Publishers, New Delhi, India.

Salama, Z.A.; El-Fouly, M.M. and Gaafor, A.A. (2013). Mitigation of the adverse effect of salinity through stimulation some secondary metabolites and antioxidant enzymes of methanolic extract of maize cultivars by exogenous ascorbic acid. J. of Food Agric. and Environ., 11: 1328-1335.

Slinkard, J. and Singleton, V.L. (1977). Total phonel analysis: automation and comparison with manual methods. Amer. J. of Enology and Viticulture, 28: 49-55.

Snehlata, H.S. and Payal, D.R. (2012). Fenugreek (Trigonella foenumgraecum L.): An Overview. Int. J. Curr. Pharm. Rev. Res. 2: 169-187.

Tahir, M.M.; Khurshid, M.; Khan, M.Z.; Abbasi, M.K. and Kazmi, M.H. (2011). Lignite-derived humic acid effect on growth of wheat plants in different soils. Pedosphere, 21: 124-131.

Trevisan, S.; Francioso, O.; Quaggiotti, S. and Nardi, S. (2010). Humic substances biological activity at the plant-soil interface, from environmental aspects to molecular factors. Plant Signaling, Behavior, 5: 635-643. 
Tugrul, L. and Ozer A. (1985). Possibilities for the use of Trigonella foenumgraecum L. seeds as a crude drug in Turkey. Acta Pharmaceutica Turcia. 27: 14-16.

Turky Neveen, S.M.A. (2007). Physiological studies on snap bean plants. M. Sci. Thesis, Fac. Agric., Cairo Univ., Egypt.

Vaughan, D. and Ord, B.G. (1991). Influence of natural and synthetic humic substances on the activity of urease. Eur. J. Soil Sci., 42:17-23.

Wagner, H.; Bladt, S. and Zgainski, E.M. (1984). Plant Drug Analysis: A Thin Layer Chromatography Atlas. Translated by Scott, Th. A. Springer-Verlage, Berlin, and Heidelberg. New York, 51-54.

Yang, H.L.; Hseu, Y.C.; Hseu, Y.T.; Lu, F.J.; Lin, E. and Lai, J.S. (2004). Humic acid induces apoptosis in human premyelocytic leukemia HL-60 cells. Life Sc., 75: 1817-1831.

Zhang, L.X.; Lai, J.H.; Gao, M. and Ashraf, M. (2014). Exogenous glycinebetaine and humic acid improve growth, nitrogen status, photosynthesis, and antioxidant defense system and confer tolerance to nitrogen stress in maize seedlings. J. of Plant Interactions, 9: 159-166.

Zhang, X. and Ervin, E.H. (2004). Cytokinin-containing seaweed and humic acid extract associated with creeping bent gross leaf cytokinins and drought resistance. Crop Sci., 44: 1737-1745.

Zhishen, J.; Mengcheng, T. and Jianming, W. (1999). The determination of flavonoid percentages in mulberry and their scavenging effects on superoxide radicals. Food Chem., 64: 555-559.

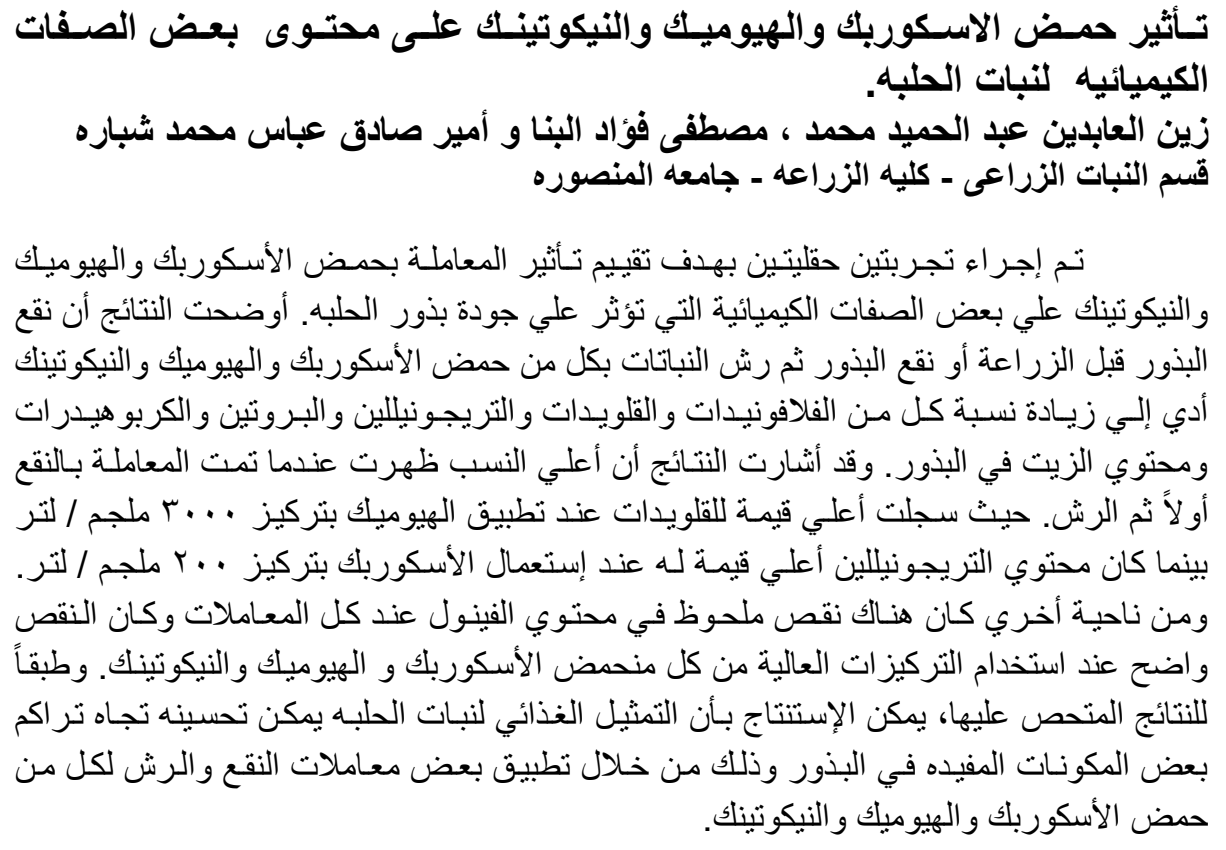

